\title{
Urgensi dan Legitimasi Fatwa Majelis Permusyawaratan Ulama Aceh Nomor 3 Tahun 2018 tentang Penetapan Arah Kiblat
}

\author{
Ismail \\ Jurusan Ilmu Falak Fakultas Syariah IAIN Lhokseumawe \\ Jalan Medan-Banda Aceh, No. 1, Buket Rata, Muara Dua, Kota Lhokseumawe, Aceh \\ E-mail:ismail@iainlhokseumawe.ac.id
}

\begin{tabular}{llll}
\hline Submit & $: 12$ Maret 2020 & Diterima & $:$ 18 Mei 2020 \\
Revisi & $: 15$ April 2020 & Terbit & $:$ 03 Juni 2020 \\
\hline
\end{tabular}

\begin{abstract}
Abstrak: Saat umat Islam sudah menetap di seluruh permukaan bumi, salah satu persoalan yang menjadi titik perhatiannya adalah arah kiblat. Bagi umat Islam, arah kiblat tidak hanya kebutuhan untuk salat yang merupakan salah satu syarat sahnya salat saja, namun juga termasuk untuk keperluan lain yang berkaitan dengan kiblat seperti posisi menguburkan jenazah, mendirikan masjid dan mushalla. Tulisan ini menjelaskan kedudukan fatwa MPU Aceh Nomor 3 Tahun 2018 tentang penetapan arah kiblat dari fatwa MUI nomor 3 dan 5 Tahun 2010 tentang arah kiblat dan menjelaskan relevansi dengan konteks. Dengan pendekatan ilmu falak, dapat dijelaskan bahwa kedudukan fatwa MPU Aceh Nomor 3 Tahun 2018 tentang penetapan arah kiblat menjadi penyempurna dari fatwa MUI Nomor 3 dan 5 tahun 2010 tentang arah kiblat. Penyempurnaan pada integritas dan intensitas fatwa yang bersifat responsif, proaktif dan antisipatif. Kehadiran fatwa MPU Aceh tentang penetapan arah kiblat mampu menyelesaikan problem tentang arah kiblat di Indonesia, baik pada ranah teknis maupun pada ranah sosiologis, karena isi fatwa sangat sesuai dengan konteks dan telah terakomodir dimensi sains, teknologi dan fikih sebagai salah satu ciri ijtihād jamā̄i
\end{abstract}

Kata kunci: Fatwa, MPU Aceh, Fatwa MUI, Arah Kiblat, Ilmu Falak

Abstract: When Muslims have settled on the earth, one of the problems which become a focus of attention is the Kiblah direction. For Muslims, the Kiblah direction is not only the need for prayer which is one of the legitimate conditions of prayer, but also includes other needs related to Kiblah such as the position of burying the body, establishing a mosque and musalla. This paper explains the position of the MPU Aceh's fatwa Number 3 of 2018 concerning the determination of the direction of the MUI of the fatwa of MUI number 3 and 5 of 2010 concerning the direction of Kiblah and explaining its relevance to the context. With the approach of astronomy, the position of the MPU Aceh fatwa Number 3 of 2018 concerning the determination of the direction of Kiblah is complementary to the MUI fatwa Number 3 and 5 of 2010 concerning the Kiblah direction. Improvements to the integrity and intensity of fatwas are responsive, proactive and anticipatory. The presence of the MPU Aceh's fatwa on Kiblah direction was able to solve the problem of Kiblah's direction in Indonesia, both in the technical and the sociological domain because the content of the fatwa is relevant with the context and accommodated the dimensions of science, technology and Figh as a characteristic of Ijtihad Jama'i.

Keywords: Fatwa, MPU Aceh, MUI Fatwa, Kiblah Direction, Islamic astronomy 


\section{Pendahuluan}

Bagi umat Islam, mengetahui arah kiblat bukan hanya untuk kebutuhan salat atau mendirikan masjid agar tepat menghadap arah kiblat, namun hukum yang sama juga berlaku saat pemakaman jenazah dan hal-hal lain yang ada kaitan hukum dengan kiblat, baik hukum wajib, sunat, makruh dan haram. ${ }^{1}$ Oleh karenanya, kehadiran fatwa ulama tentang arah kiblat menjadi suatu yang dinantikan oleh semua kalangan masyarakat pencari kepastian hukum, dimana dengan adanya fatwa dapat menyelesaikan masalah yang telah ada, baik dalam ranah teknis, maupun ranah sosiologis. ${ }^{2}$ Semua fatwa lahir tidak dalam kondisi yang kosong, pasti ada hal lain yang melatarbelakanginya, fakta sosial memang selalu mendominasinya.

Tulisan mengenai arah kiblat memang sudah tergolong banyak di Indonesia, mulai dari pembahasan mengenai metode yang akurat dalam menghitung azimut kiblat (Ahmad Izzuddin, 2012), modifikasi peralatan pengukuran arah kiblat (Hakim, Raharjo dan Waluyo, 2013), verifikasi fatwa MUI tentang arah kiblat (Agus Yusrun Nafi', 2015), maupun standar operasional prosedur (SOP) kalibrasi arah kiblat (Ismail, 2019). Namun sejauh amatan penulis, belum ada tulisan yang membahas tentang fatwa Majelis Permusyawaratan Ulama (MPU) Aceh tentang penetapan arah kiblat. Tulisan ini menjadi penting, mengingat di Indonesia sebelumnya telah ada fatwa Majelis Ulama Indonesia (MUI) tentang arah kiblat sebagai respon terhadap persoalan kiblat umat Islam di Indonesia, yakni fatwa MUI Nomor 3 dan Nomor 5 Tahun 2010 yang secara nasional mungkin sudah dianggap sempurna sebagai landasan hukum mengenai arah kiblat di Indonesia. Realitas di Aceh tahun 2018 MPU Aceh juga mengeluarkan fatwa tentang penetapan arah kiblat.

Tulisan ini mencoba menjelaskan urgensi dan legitimasi fatwa MPU Aceh nomor 3 tahun 2018 tentang penetapan arah kiblat, mengingat lahir fatwa ini setelah lahir fatwa MUI tahun 2010 dalam masalah yang sama. Kehadiran fatwa MPU Aceh Nomor 3 Tahun 2018 tentang penetapan arah kiblat menjadi topik diskusi penting bagi akademisi, khususnya yang menggeluti dalam bidang ilmu falak, mengingat sebelum nya sudah ada fatwa MUI Nomor 3 Tahun 2010 tentang arah kiblat dan direvisi dengan lahir fatwa MUI Nomor 5 pada tahun yang sama, yaitu tahun 2010. Kehadiran fatwa MUI Nomor 3 Tahun 2010 dianggap hanya lahir dari satu sudut pandang, yaitu ilmu fikih, tidak mengakomodir dimensi ilmu falak, sehingga hasil fatwa dianggap pramatur, kurang cocok dengan konteks keindonesiaan yang sudah berkebang ilmu falak dan sudah ada tim pengukur arah kiblat yang ditugaskan oleh negara melalui Kementerian Agara Republik Indonesia. Lahirnya fatwa MUI nomor 5 Tahun 2010 sebagai revisi fatwa sebelumnya dianggap sudah mengakomodir dimensi fikih dan ilmu falak. ${ }^{3}$

\section{Fatwa MUI tentang Penetapan Arah Kiblat}

Di Indonesia yang manyoritas masyarakat menganut agama Islam tentunya persoalan arah kiblat sudah menjadi pembahasan dan pembelajaran semenjak usia dini, mengingat persoalan kiblat banyak kaitannya dengan ibadah penting umat Islam, seperti salat, mendirikan masjid, menguburkan

\footnotetext{
Mohd Kalam Daud dan Muhammad Kamalussafir, “Akurasi Arah Kiblat Komplek Pemakaman Ditinjau Menurut Kaidah Trigonometri (Studi Kasus di Kecamatan Syiah Kuala Kota Banda Aceh)," Samarah: Jurnal Hukum Keluarga dan Hukum Islam 2 , no. 2 (29 Mei 2019): 502-29, https://doi.org/10.22373/sjhk.v2i2.4750.

Muh. Ma'rufin Sudibyo, Sang Nabi Pun Berputar, Arah kiblat dan tata cara pengukurannya. (Solo: Tinta Medina, 2011). 167-76

Agus Yusrun Nafi', “Verifikasi Fatwa Mui Nomor 03 Tahun 2010 tentang Arah Kiblat," Mahkamah : Jurnal Kajian Hukum Islam 9 , no. 1 (26 Februari 2016), https://doi.org/10.24235/mahkamah.v9i1.289.
} 
jenazah muslim dan banyak persoalan ibadah lain yang diajurkan menghadap kiblat. Namun pemahaman masyarakat terhadap konsep arah kiblat masih berbeda-beda seiring dengan perbedaan yang terjadi dalam pembahasan fukaha (mazhab Syafi'i yang tergolong ketat, harus 'ainul Ka'bah, mazhab Maliki, Hanafi dan Hambali membolehkan mengadap jihāt Ka'bah), ada yang berpendapat 'ainul Ka'bah dan ada yang berpendapat menghadap ke arah Ka'bah saja. ${ }^{4}$

Warisan ilmu megukur arah kiblat juga sudah berubah, ulama dulu menggunakan teori trigonometri planar yang mengasumsikan bentuk bumi datar, sekarang sudah menggunakan teori trigonometri bola dengan asusi bumi berbentuk bulat seperti bola. Perbedaan ini menunjukkan persoalan arah kiblat adalah persoalan ijtihadi, bukan persoalan yang sudah pasti. ${ }^{5}$ Oleh sebab itu, kehadiran fatwa ulama di Indonsia tentang arah kiblat bisa diartikan sebagai hasil ijtihad yang berlaku untuk masyarakat muslim Indonesia saat ini.

1. Fatwa MUI Nomor 3 Tahun 2010

Fatwa Majelis Ulama Indonesia (MUI) Nomor 3 Tahun 2010 tentang arah kiblat ditetapkan di Jakarta tanggal 1 Februari 2010 bertepatan dengan tanggal 16 Safar 1431 H. Dalam pertimbangan terlihat dengan jelas bahwa lahirnya fatwa ini dilatarbelakangi oleh informasi pelencengan arah kiblat masjid yang menjadi keresahan masyarakat. Dalam mengeluarkan fatwa tentang arah kiblat, MUI mengacu kepada Alquran dan hadis, serta mempertimbangkan pendapat fukaha dan pendapat pakar, dalam hal ini MUI memilih makalah KH. Ali Mustafa Ya'qub dan pendapat hasil rapat komisi fatwa. ${ }^{6}$

Ada 3 butir fatwa tentang kiblat dan satu rekomendasi yang tercantum dalam fatwa MUI Nomor 3 tahun 2010. Pertama, kiblat bagi orang yang salat dan dapat melihat Ka'bah adalah menghadap ke bangunan Ka'bah ('ainul Ka'bah). Kedua, kiblat bagi orang yang salat dan tidak dapat melihat Ka'bah adalah arah Ka'bah (jihāt al-Ka'bah). Ketiga, letak geografis Indonesia yang berada di bagian timur Ka'bah/Mekkah, maka kiblat umat Islam Indonesia adalah menghadap ke arah barat. Sedangkan rekomendasi adalah setiap bangunan masjid atau mushalla di Indonesia sepanjang menghadap ke arah barat, tidak perlu diubah, dibongkar dan sebagainya. ${ }^{7}$ Bila dianalisa dari hasil fatwa dalam ketetapan fatwa MUI nomor 3 tahun 2010 terlihat dengan jelas bahwa materi pertimbangan hanya kepada teori ilmu fikih saja, belum tersentuh kepada ilmu falak dan ilmu sosial keindonesiaan, belum terpenuhi ijtihad kolektif sebagaimana mestinya sebuah fatwa dilahirkan.

2. Fatwa MUI Nomor 5 Tahun 2010

Fatwa MUI Nomor 5 Tahun 2010 tentang kiblat merupakan revisi dari fatwa sebelumnya yang dianggap keliru oleh banyak pihak, terutama dari kalangan ulama falakiyah. Kekeliruan fatwa MUI Nomor 3 Tahun 2010 terdapat pada dua hal, pertama pendekatan dalam berfatwa yang hanya menggunakan dalil syar'i (hadis tentang kiblat) tanpa mempertimbangkan ilmu sains tentang konsep arah kiblat. Kedua pada penetapan fatwa terdapat kekeliruan di poin 3 (tiga), yaitu menyebutkan kiblat Indonesia adalah arah barat, padahal yang sebenarnya arah kiblat Indonesia secara ilmu falak adalah arah barat serong ke utara sekitar 22 - 26 derajat. ${ }^{8}$

Atas dasar kritikan dan masukan dari semua pihak terhadap isi fatwa, maka Majelis Ulama

\footnotetext{
Ahmad Izuddin, Akurasi Metode-metode Penentuan Arah Kiblat., I (Jakarta: Kementerian Agama RI, 2012). 40-45

Abdullah Ibrahim, Ilmu Falak: Antara Fiqih dan Astronomi, 1 ed. (Yogyakarta: Fajar Pustaka Baru, 2017). 66-75.

Majelis Ulama Indonesia, "Fatwa MUI Nomor 3 Tahun 2010 Tentang Arah Kiblat” (2010).

Majelis Ulama Indonesia.

Nafi', "Verifikasi Fatwa Mui Nomor 03 Tahun 2010 tentang Arah Kiblat."
} 
Indonesia pada tanggal 1 Juli 2010 bertepatan pada tanggal 18 Rajab 1431 H mengeluarkan fatwa nomor 5 dengan menyempurnakan isi fatwa pada poin tiga dan rekomendasi. Pada awalnya poin nomor tiga berisi arah kiblat Indonesia adalah arah barat, direvisi menjadi arah kiblat Indonesia adalah mengahdap ke Barat laut dengan posisi bervariasi sesuai dengan letak kawasan masingmasing. Dalam rekomendasi juga terdapat perubahan dari sebelumnya saf masjid tidak perlu dirobah menjadi perintah untuk mengubah saf masjid atau mushalla yang tidak tepat arak kiblatnya. ${ }^{9}$

3. Fatwa MPU Aceh Nomor 3 Tahun 2018

Majelis Permusyawaratan Ulama (MPU) Aceh merupakan sebuah lembaga yang dilindungi dan diatur secara sah oleh undang-undang Negara Kesatuan Reublik Indonesia yaitu, Undangundang Nomor 44 Tahun 1999 Tentang penyelenggaraan keistimewaan Provinsi Daerah Istimewa Aceh, Undang-undang Nomor 11 Tahun 2006 Tentang pemerintahan Aceh, Qanun Provinsi Nanggro Aceh Darussalam Nomor 11 Tahun 2002 Tentang pelaksanaan Syariat Islam bidang aqidah, ibadah dan syiar Islam, Qanun Aceh Nomor 9 Tahun 2003 tentang hubungan tata kerja MPU dengan eksekutif, legeslatif dan instansi lainnya, Qanun Aceh Nomor 8 Tentang Majelis Permusyawaratan Ulama dan Qanun Aceh Nomor 8 Tahun 2014 Tentang pokok-pokok syari'at Islam.

Atas dasar amanat dari Undang-undang dan Qanun Provinsi Aceh yang berlaku, MPU Aceh mengeluarkan fatwa menyangkut dengan penetapan arah kiblat. Penyebab lahirnya fatwa MPU Aceh Nomor 3 Tahun 2018 sama halnya dengan lahir fatwa MUI Nomor 3 dan Nomor 5 Tahun 2010, yaitu timbul perselisihan pendapat mengenai arah kiblat yang sudah sampai pada tingkat kegelisahan masyarakat umum. Dalam penetapan atau perumusan fatwa tentang arah kiblat, MPU Aceh ada melibatkan ahli falak, yaitu pertama Tgk. H. Abdullah Ibrahim, selain beliau anggota MPU Aceh, termasuk juga salah satu ahli falak tertua yang ada di Aceh saat ini. Kedua Alfirdaus Putra, selain anggota Badan Hisab Rukyat Provinsi Aceh, beliau juga salah satu tim pengukur arah kiblat di Kanwil Provinsi Aceh. Ketiga Suhrawardi Ilyas, beliau selain Dosen Geologi Universitas Syah Kuala (Unsyiah) juga termasuk yang banyak berkecimpung dalam bidang ilmu falak atau persoalan hisab rukyat di Aceh. ${ }^{10}$

Setelah memperhatikan pendapat para ahli falak dan mengingat dasar penetapan hukum dari MPU Aceh yaitu al-Quran, Hadis, Ijma' Ulama, Qiyas, kaidah ushul fiqh/fiqh dan pendapat ulama, maka MPU Aceh menetapkan enam (6) poin fatwa dan dua (2) taushiyah. Poin pertama, kiblat adalah bangunan Ka'bah. Kedua, menghadap kiblat dalam salat adalah wajib. Ketiga, kiblat bagi orang yang salat dapat melihat Ka'bah adalah menghadap ke bangunan Ka'bah. Keempat, kiblat bagi orang salat dan tidak dapat melihat Ka'bah adalah bangunan Ka'bah secara zannī. Kelima, setiap ibadah salat yang dikerjakan menghadap ke arah bangunan Ka'bah secara zannī berdasarkan ijtihad pertama dan kedua adalah sah. Keenam, setiap pendirian tempat ibadah salat wajib diteliti arah kiblat oleh ahli. Sedangkan taushiyah pertama, diharapkan kepada pemerintah, tokoh masyarakat dan pengurus masjid untuk menerima hasil penelitian arah kiblat oleh para ahli. Kedua, diharapkan kepada pemerintah, tokoh masyarakat dan pengurus masjid untuk meluruskan arah kiblat tempat ibadah salat. ${ }^{11}$

10 Majelis Permusyawaratan Ulama, “Fatwa MPU Aceh Nomor 3 Tahun 2018 Tentan Penetapan Arah Kiblat," Pub. L. No. 2018 (t.t.).

11 Majelis Permusyawaratan Ulama.
} 
Dari tiga fatwa di atas terlihat jelas saling menyempurnakan, fatwa MUI Nomor 3 Tahun 2010 disempurnakan oleh fatwa MUI Nomor 5 Tahun 2010 dan fatwa MUI Nomor 5 Tahun 2010 disempurnakan oleh fatwa MPU Aceh Nomor 3 tahun 2018. ${ }^{12}$ Fatwa MPU Aceh Nomor 3 Tahun 2018 tentang penetapan arah kiblat sudah tergolong sangat sempurna, hal ini bisa dilihat dari metode penetapan hukum dalam mengeluarkan fatwa dan telah terakomodir konteks kekinian dalam masalah ilmu pengetahun dan gejolak sosial dalam bidang arah kiblat, dalam arti lain semua syarat ijtihad jama’i (ijtihad kolektif) yang harus dipedomani oleh lembaga fatwa telah terpenuhi. Selain tuntas dalam dalil syar'i, fatwa ini terlihat ada penekanan menggunakan ilmu sains dan ilmu falak dalam berijtihad arah kiblat seperti yang tercantum pada poin kelima dan keenam. Selain itu, fatwa ini juga menjaga kerukunan sosial dalam persoalan kiblat dengan merekomendasikan hanya tim ahli yang bisa menetapkan arah kiblat, namun ahli disini harus artikan dalam makna sistem yaitu sebuah tim yang tergabung dan berwewenang dalam menetapkan arah kiblat secara peraturan. Dalam hal ini tentunya yang berwewenang adalah tim dari Kementerian Agama di setiap Kabupaten/Kota yang melibatkan tokoh masyarakan dan pengurus masjid sebagai ahli dalam penetapan arah kiblat, baik sebagai pengukur atau terlibat sebagai saksi. Intinya, fatwa MPU Aceh Nomor 3 Tahun 2018 telah terpenuhi ketentuan umum dan sifat fatwa, yaitu responsif, proaktif dan antisifatif. ${ }^{13}$

\section{Ijtihad Kiblat dan Tim Ahli}

Dalam fatwa MPU Aceh Nomor 3 Tahun 2018 tentang penentuan arah kiblat ada dua hal yang perlu diperjelas dan dipertegas agar mudah dipahami dalam menjalankan hasil fatwa sebagaimana mestinya, yaitu masalah ijtihad dan tim ahli sebagaimana tersebut dalam poin fatwa nomor lima dan enam. Untuk menemukan titik temu pemahaman terhadap dua konsep tersebut, penulis menggali konsep tersebut melalui pendekatan ilmu sosial, ilmu fikih, ushul fikih dan ilmu falak. Hal ini penulis lakukan, mengingat latar belakang lahir fatwa MPU Aceh Nomor 3 Tahun 2018 tentang penentuan arah kiblat bukan hanya masalah dalil fikih, namun masuk di dalamnya masalah sosial dalam pengukuran arah kiblat dan kalibrasi arah kiblat masjid yang dianggap bangunannya tidak tepat mengarah ke Ka'bah.

Dalam ushul fiqh terlihat banyak definisi tentang ijtihad, namun menurut Amir Syarifuddin semua definisi itu tidak ada perbedaan yang berarti, semua definisi ijtihad saling menguatkan dan menyempurnakan. Dari semua definisi tentang ijtihad dapat diambil beberapa poin inti yang harus ada agar disebutkan sebagai aktifitas ijtihad. Pertama, ijtihad adalah mempergunakan daya nalar semaksimal mungkin. Kedua, ijtihad dilakukan oleh orang yang telah memiliki kemampuan dalam bidang ilmu tertentu yang disebut ahli dalam ilmu tersebut. Ketiga, hasil ijtihad merupakan dugaan yang paling kuat tentang sebuah hukum yang bersifat amaliah. Dan keempat, ijtihad dilakukan secara ilmiah. ${ }^{14}$

Untuk persoalan arah kiblat, ijtihad merupakan sebuah upaya untuk mengetahui arah kiblat dengan patokan kepada tanda yang mampu memberi petunjuk posisi Ka'bah. Tanda yang mampu menunjuki posisi Ka’bah sangat banyak, namun menurut Imam Khatib Syirbīin dalam kitab Mugni al-

\footnotetext{
12 Ismail, "Standar Operasional Prosedur (SOP) Kalibrasi Arah Kiblat Masjid Di Era Digital," Al-Marshad:Jurnal Astronomi Islam Dan Ilmu-Ilmu Berkaitan 5, no. 1 (2 Juni 2019), https://doi.org/10.30596/jam.v5i1.3126.

13 Achmad Jaelani dkk., Hisab Rukyat Menghadap Kiblat (Figh, Aplikasi Praktis, Fatwa, dan Software) (Pustaka Rizki Putra, 2012$) .114$.

14 Amir Syarifuddin, Ushul Figh, Pertama (Jakarta: Kencana, 2011). 240.
} 
muhtāj, tanda yang paling kuat untuk petunjuk arah posisi Ka'bah adalah benda langit seperti bintang Polaris dan tanda yang paling lemah adalah pedoman arah tiupan angin.

$$
\text { (وأمكن الاجتهاد) بأن كان بصيرا يعرف أدلة القبلة وهي كثيرة: أضعفها الرياح لاختلآها، وأقواها القطب.. }
$$

Artinya: (dan mungkin untuk berijtihad) dengan cara adalah kondisi seseorang itu bisa melihat yang mengetahui ia akan petunjuk arah kiblat dan petunjuk arah kiblat itu sangat banyak: yang paling lemah dari semua petunjuk adalah arah hembusan angin karena hembusan angin bisa berubah-ubah, dan yang paling kuat dari semua petunjuk adalah bintang Polaris.

Ijtihad dalam konteks penetapan arah kiblat adalah berupaya semaksimal mungkin untuk menemukan arah posisi Ka'bah dengan menggunakan petunjuk atau instrumen yang paling akurat yang didapati di sebuah daerah. Instrumen yang mampu menunjuki arah kiblat sekarang sangat banyak, seperti kompas manual, kompas digital, rubu' mujayyab, istiwä' 'aini, mizwala, qiblat tracker dan theodolit. ${ }^{16}$ Dari semua alat tersebut ada yang berpatokan pada matahari, bayang matahari dan berpatokan pada titik utara magnet bumi. Bila diurutkan dari semua instrumen tersebut, maka theodolit merupakan alat petunjuk arah kiblat yang paling akurat untuk saat ini, hal ini dikarenakan theodolit langsung berpatokan pada nilai matahari, bukan pada bayang matahari dan mampu mengaplikasikan nilai petunjuk arah sampai dalam skala detik busur. ${ }^{17}$

Setelah dasar hukum penetapan arah kiblat ada, baik dalam fatwa MUI Nomor 3 dan 5 Tahun 2010, maupun fatwa MPU Aceh Nomor 3 Tahun 2018, berikutnya siapa yang berhak dalam menetapkan arah kiblat untuk kebutuhan umum seperti masjid, mushalla dan perhotelan? Hal ini menjadi penting, karena salah satu yang menjadi pemicu konflik sosial dalam masyarakat tentang arah kiblat adalah klaim metode penentuan orang dahulu lebih akurat dan mahir dalam menentukan arah kiblat sehingga bagaimanapun hasil pergeseran masjid secara nyata tidak boleh dirubah lagi. Secara tanggung jawab kenegaraan, pemerintah melalui Kementerian Agama RI telah mengeluarkan Peraturan Menteri Agama (PMA) Nomor 13 Tahun 2012 tentang organisasi dan tata kerja instansi vertikal Kementerian Agama. Pada Bab I pasal 30 dan 31 dapat disimpulkan bahwa setiap kantor Kementerian Agama di setiap Kabupaten/Kota di seluruh Indonesia ada bidang urusan agama Islam dan pembina syariah dimana salah satu tugas pokok sebagai mana diatur dalam pasal 31 huruf $b$ adalah hisab rukyat. Tugas hisab rukyat tentunya masuk semua persoalan hisab rukyat yang ada kaitannya dengan ibadah umat Islam, seperti arah kiblat, waktu salat, penetapan awal bulan Hijriah dan informasi peristiwa gerhana.

Atas dasar PMA tersebut, di Indonesia yang berhak menetapkan arah kiblat, mengeluarkan sertifikat dan berita acara pengukuran arah kiblat tempat umum adalah tim hisab rukyat dari Kementerian Agama di Kabupaten/Kota masing-masing. Namun, selain harus ada orang yang diakui ahli dalam bidang ilmu falak, untuk memenuhi unsur sosial, agama dan sains, Kementerian Agama saat menetapkan arah kiblat di sebuah masjid perlu melibatkan tokoh agama dan masyarakat setempat yang masuk pada daftar nama-nama saksi dalam berita acara pengukuran arah kiblat. Berita acara ini wajib ada di setiap masjid, karena akan menjadi pedoman bagi masyarakat dalam mengikuti arah bangunan sebuah masjid sebagaimana tercantum dalam poin nomor enam dalam

\footnotetext{
15 Imam Khatib al-Syarboini, Mugni al-Mukhtāj, 2 vol. (Lebanon: Bairot, 2004). 203.

16 Teungku Mustafa Muhammad Isa, Fiqih Falakiyah (Yogyakarta: Deepublish, 2016). 141-144.

17 Isa.
} 
fatwa MPU Aceh dan atas dasar berita acara inilah seseorang sah salat menghadap arah kiblat zanni sebagaimana tertulis pada poin kelima dalam fatwa MPU Aceh Nomor 3 Tahun 2018. Oleh karenanya, setiap masjid, mushalla dan perhotelan wajib ada berita acara penetapan arah kiblat yang dikeluarkan oleh Kementerian Agama sebagai yang bertanggung jawab. Bila ada masjid belum ada berita cara penetapan arah kiblat, masyarakat masih wajib berijtihad disetiap hendak melaksanakan salat di masjid tersebut.

\section{Kiblat Zannï dan Kiblat Jihāt}

Kiblat zannī menjadi hal yang penting untuk dibahas, mengingat dalam fatwa MPU Aceh nomor 3 Tahun 2018 pada poin keempat menyebutkan bahwa kiblat salat bagi orang yang tidak dapat melihat Ka'bah adalah kiblat zanni dan pada poin kelima menyebutkan bahwa menghadap kiblat yang sah bagi orang salat dan jauh dari Ka'bah adalah arah kiblat zanni. Jadi, sebenarnya apa yang dimaksud kiblat zannī. Untuk menjawab maksud dari kiblat zannī, harus ditelusuri konsep arah kiblat dalam ilmu falak dan fikih.

Dalam fikih, dikenal ada tiga konsep arah kiblat. Pertama, 'ayn al-Ka'bah yaitu arah kiblat bagi orang yang dapat melihat Ka'kbah. Kedua, jihat al-Ka'bah yaitu kiblat bagi orang yang tidak dapat melihat Ka'bah tetapi dapat melihat Masjidil Haram. Ketiga,jihāt al-qiblah yaitu arah kiblat bagi orang yang jauh dari kota Mekkah tetapi mampu berijtihad untuk menemukan arah posisi Ka'bah dengan menggunakan ilmu dan instrumen yang dimilikinya. ${ }^{18}$ Semua ulama mazhab fikih menyepakati bahwa kiblat bagi orang yang dapat melihat Ka'bah adalah bagunan Ka'bah itu sendiri, namun bila jauh dari Ka'bah seperti Aceh, selain mazhab Syafi'i membolehkan menghadap ke jihāt al-Ka'bah. Sedangkan dalam mazhab Syafi'i tetap harus menghadap 'ayn al-Ka'bah dengan menggunakan kemampuan dirinya atau orang yang ahli dalam menentukan arah kiblat. Konsep ini dikenal dengan kiblat zanni atau jihàt al-qiblah. Perbedaan pendapat fukaha terhadap arah kiblat bukan pada persoalan dalil, namun pada interpretasi dalil dengan pendekatan yang berbeda, yakni pendekatan keterlihatan Ka'bah dan tidaknya. Untuk konteks sekarang dengan pendekatan ijtihad arah posisi Ka'bah dengan pendekatan sains dan teknologi akan terdapat kesepakatan bahwa arah kiblat adalah arah terdekat dari suatu tempat ke Ka'bah dan akan terlepas dari terlihat atau tidaknya Ka'bah. ${ }^{19}$

Dalam ilmu falak, konsep arah atau azimut ditentukan searah jarum jam pada lingkaran horizon dalam konstruksi bumi seperti bola yang diawali pada titik utara sampai titik timur 90 derajat busur, dari titik timur ke titik selatan ditambah 90 derajat menjadi 180 derajat, dari titik selatan ke titik barat ditambah 90 derajat menjadi 270 derajat dan dari titik barat ke titik utara ditambah 90 derajat menjadi 360 derajat. ${ }^{20}$ Setiap satu sudut bernilai 90 derajat dan satu lingkaran sempurna adalah 360 derajat. Jadi arah kiblat dalam ilmu falak arah posisi Ka'bah yang ditunjuki dengan nilai azimut yang sesuai dengan lokasi masing-masing di seluruh permukaan bumi. Untuk konsep jihāt al-Ka'bah, boleh disebutkan satu sudut dengan nilai 90 derajat atau digabung dua sudut menjadi 180 derajat dengan titik tengahnya berada pada posisi Ka'bah. ${ }^{21}$ Sedangkan untuk konsep jihāt al-qiblah atau kiblat zannī

\footnotetext{
18 Kemenag RI, Ilmu Falak Praktik, 2013, http://simbi.kemenag.go.id/pustaka/ images/materibuku/ilmu\%20falak\%20 paraktik-2013.pdf.

19 Dhiauddin Tanjung, “Urgensi Kalibrasi Arah Kiblat dalam Penyempurnaan Ibadah Salat," Al-Manahij: Jurnal Kajian Hukum Islam 11, no. 1 (2017): 113-32, https://doi.org/10.24090/mnh.v11i1.1273.

20 Slamet Hambali, Ilmu Falak, Arah Kiblat Setiap Saat. (Yogyakarta: Pustaka Ilmu, 2013). 14-15

${ }^{21}$ Abdullah Ibrahim, Ilmu Falak: Antara Fiqih dan Astronomi. 62-84.
} 
adalah nilai sudut yang dihasilkan di suatu tempat dari titik kutup utara ke titik Ka'bah. Dalam menghitung arah kiblat, bumi cukup dianggap berbentuk bola sempurna, karena tidak jauh berbeda hasil perhitungan arah kiblat antara bumi berbentuk bola, ellipsoida dan geoida. ${ }^{22}$

Dari uraian di atas dapat disimpulkan bahwa yang dimaksud dengan kiblat zannī adalah arah terdekat suatu tempat ke Ka'bah yang berpatokan pada lingkaran besar bola bumi (360 derajat) yang melewati suatu tempat dan Ka'bah. Arah terdekat ditunjuki oleh nilai azimut yang dihitung menggunakan teori geometri bola dan diimplementasikan dengan instrumen yang paling akurat yaitu theodolit. Kiblat jihat adalah suatu sudut arah (90 derajat) yang Ka'bah berada di tengahnya. Menghadap kiblat dalam konsep jihad adalah menghadap salah satu arah dalam rentang 90 derajat dimana posisi Ka'bah berada yaitu 45 derajat dari posisi Ka'bah ke kanan dan 45 derajat dari Ka'bah ke kiri. Namun perlu diketahui, untuk jarak lokasi seperti Aceh, satu derajat selisih dari Ka'bah bisa melenceng 111-kilometer dari posisi Ka'bah. ${ }^{23}$

\section{Toleransi Pelencengan Arah Kiblat}

Dalam ilmu falak, tidak dikenal toleransi pelencengan arah kiblat, karena dengan menggunakan teori geometri posisi Ka'bah sebagai arah kiblat bisa dihitung dengan keakuratan sampai pada skala detik busur. ${ }^{24}$ Toleransi pelencengan arah kiblat atas dasar hadis Nabi Muhammad Saw. yang menjelaskan Ka'bah sebagai kiblat bagi orang dalam Masjidil Haram, Masjidil Haram kiblat bagi orang Mekkah dan Tanah Haram menjadi kiblat bagi penduduk bumi. Luas tanah haram dengan panjang jari-jari 45-kilometer dijadikan batas toleransi pelencengan arah kiblat dari posisi Ka'bah. Bagi daerah yang jauh dari Ka'bah seperti Indonesia, konsep teleransi ini perlu dibangun, mengingat sangat sulit mendirikan bangunan masjid, mushalla dan tempat ibadah umum lainnya yang mampu seakurat hasil perhitungan. Nilai toleransi pelencengan arah kiblat sangat diperlukan oleh tim ahli saat melakukan kalibrasi arah kiblat masjid.

Untuk menghitung batas toleransi pelencengan arah kiblat untuk Provinsi Aceh, bisa saja diambil sampel perhitungan masjid Islamic Center Kota Lhokseumawe dengan koordinat 05 10' 49" LU $97^{\circ} 08^{\prime} 31^{\prime \prime}$ BT, setelah data didapatkan lalu dilakukan tahapan-tahapan sebagai berikut.

1. Data yang diperlukan

$$
\begin{aligned}
& \mathrm{L} 1=5^{\circ} 10^{\prime} 49^{\prime \prime} \mathrm{LU} \\
& \mathrm{B} 1=97^{\circ} 8 \text { ' 31" BT } \\
& \mathrm{L} 2=21^{\circ} 25^{\prime} 21^{\prime \prime} \mathrm{LU} \text { (Lintang Ka'bah) } \\
& \text { B2 }=39^{\circ} 49^{\prime} 34^{\prime \prime} \text { BT (Bujur Ka'bah) }
\end{aligned}
$$

2. Menghitung sudut dan sisi.

$$
\begin{aligned}
\text { Sisi a } & =90^{\circ}-\mathrm{L} 1 \\
& =90^{\circ}-5^{\circ} 10^{\prime} 49^{\prime \prime} \\
& =84^{\circ} 49^{\prime} 11^{\prime \prime} \\
\text { Sisi b } & =90^{\circ}-\mathrm{L} 2
\end{aligned}
$$

\footnotetext{
${ }_{22}$ Moehammad Awaluddin dkk., “Kajian Penentuan Arah Kiblat Secara Geodetis,” TEKNIK 37, no. 2 (31 Desember 2016): 84-87, https://doi.org/10.14710/teknik.v37i2. 12107.

23 Rinto Anugraha, Mekanika Benda Langit (Yogyakarta: MIPA UGM, 2012). 35-40.

24 Rinto Anugraha. 33-34.
} 


$$
\begin{aligned}
& =90^{\circ}-21^{\circ} 25^{\prime} 21^{\prime \prime} \\
& =68^{\circ} 34^{\prime} 39^{\prime \prime}
\end{aligned}
$$

Sudut $\mathrm{C}=\mathrm{B} 1-\mathrm{B} 2$. (Karena nilai $\mathrm{B} 1<\mathrm{B} 2$ dan $\mathrm{B} 1 \leq 180^{\circ}$, maka $\left.\mathrm{C}=\mathrm{B} 1-\mathrm{B} 2\right)$.

$$
\begin{aligned}
& =97^{\circ} 8^{\prime} 31^{\prime \prime}-39^{\circ} 49^{\prime} 34^{\prime \prime} \\
& =57^{\circ} 18^{\prime} 57^{\prime \prime}
\end{aligned}
$$

Sisi $c=\operatorname{Cos} c=\operatorname{Cos} a \operatorname{Cos} b+\operatorname{Sin} a \operatorname{Sin} b \operatorname{Cos} C$

$\operatorname{Cos} \mathrm{c}=\operatorname{Cos} 84^{\circ} 49^{\prime} 11^{\prime \prime} \operatorname{Cos} 68^{\circ} 34^{\prime} 39^{\prime \prime}+\operatorname{Sin} 84^{\circ} 49^{\prime} 11^{\prime \prime} \operatorname{Sin} 68^{\circ} 34^{\prime} 39^{\prime \prime} \operatorname{Cos} 57^{\circ}$ 18 ' 57 "

$=0,533624337\left(\right.$ shift $\cos$ Ans $\left.={ }^{\circ} "\right)$

$\mathrm{c}=57^{\circ} 44^{\prime} 57,6^{\prime \prime}$

Sudut $B=\operatorname{Sin} B=\operatorname{Sin} b \operatorname{Sin} C / \operatorname{Sin} C$

$=\operatorname{Sin}^{-}{ }^{-1}(\operatorname{Sin} b \operatorname{Sin} C / \operatorname{Sin} c)$

$=\operatorname{Sin}^{-}{ }^{1}\left(\operatorname{Sin} 68^{\circ} 34^{\prime} 39^{\prime \prime} \operatorname{Sin} 57^{\circ} 18^{\prime} 57^{\prime \prime} / \operatorname{Sin} 57^{\circ} 44^{\prime} 57,6^{\prime \prime}\right)$

$=\operatorname{Sin}^{-1}(0,926441758)\left(\right.$ shift $\operatorname{Sin}$ Ans $\left.={ }^{\circ}{ }^{\circ}\right)$

$=67^{\circ} 53^{\prime} 12,39^{\prime \prime}$

Sudut $A=\operatorname{Sin} A=\operatorname{Sin} a \operatorname{Sin} B / \operatorname{Sin} b$

$=\operatorname{Sin} 84^{\circ} 49^{\prime} 11^{\prime \prime} \operatorname{Sin} 67^{\circ} 53^{\prime} 12,39^{\prime \prime} / \operatorname{Sin} 68^{\circ} 34^{\prime} 39^{\prime \prime}$

$=0,991132669$

$=\operatorname{Sin}^{-1}(0,991132669)\left(\right.$ shift $\operatorname{Sin}$ Ans $\left.={ }^{\circ}{ }^{\prime \prime}\right)$

$=82^{\circ} 21^{\prime} 51,06^{\prime \prime}$

3. Menghitung sisi bantu dan simpangan yang diperkenankan

$$
\begin{aligned}
& \text { Sisi bantu } q=(0,0071 / \operatorname{Cos}(\mathrm{A}-90)) \\
& =\left(0,0071 / \operatorname{Cos}\left(82^{\circ} 21^{\prime} 51,06^{\prime \prime}-90^{\circ}\right)\right) \\
& =7,163521303 \\
& =\operatorname{Tan}^{-1}(7,163521303)\left(\text { shift Tan Ans }={ }^{\circ} "\right) \\
& =0^{\circ} 24^{\prime} 37,56^{\prime \prime}
\end{aligned}
$$

Jadi toleransi pelencengan arah kiblat untuk kota Lhokseumawe adalah $00^{\circ} 24^{\prime} 31^{\prime \prime}$, bisa dibulatkan menjadi $00^{\circ} 25^{\prime}$ dan data ini bisa digunakan untuk seluruh Aceh. Artinya, sebuah masjid masih dianggap akurat arah kiblat nya bila arah bangunan masih berada dalam rentang 25 menit busur dari posisi Ka'bah ke kiri atau ke kanan Ka'bah.

\footnotetext{
25 Muh. Ma'rufin Sudibyo, Sang Nabi Pun Berputar, Arah kiblat dan tata cara pengukurannya. 142-145.
} 


\section{Isu Pelengkungan Saf Masjid dan Lempengan Bumi}

Salah satu alasan bagi yang masih berpendapat boleh menghadap jihat Ka'bah adalah tidak mungkin Ka'bah yang berukuran 12 meter persegi dapat dihadap oleh para jamaah yang panjang saf masjid sampai lebih 20 meter, seharusnya saf salat yang lebih panjang dari ukuran Ka'bah harus dilengkungkan agar semua jamaah dapat berhadapan dadanya dengan bangunan Ka'bah. Alasan klasik ini mampu dituntaskan dengan merobah paradigma dalam konsep menghadap kiblat, kalau paradigma yang dibangun adalah melihat arah kiblat dengan mata, maka alasan tersebut menjadi logis. Namun bila paradigma yang dibangun adalah mengetahui arah kiblat dengan ilmu pengetahuan, maka alasan tersebut menjadi klasik.

Dalam konsep ilmu geometris, dimensi Ka'bah bagi lokasi yang jauh seperti Indonesia dapat diabaikan dari pelengkungan saf salat, dimana Ka'bah berada dalam lingkaran ekuidistan yang besar dan Ka'bah dapat diartikan sebagai sebuah titik yang berhimpit dengan pusat lingkaran ekuidistan tersebut. Sebagai ilustrasi dapat dicontonhkan bila ada sepotong tongkat dengan panjang 1-meter diletakkan pada lingkarang dengan panjang jari-jari 100-meter akan terlihat perbedaan lurus tongkat dengan bentuk lingkaran dengan panjang jari-jari 1000 kilometer. Pada lingkaran dengan jari-jari 100-meter akan terlihat tongkat tidak berhimpit dengan lingkaran dikarenakan tongkat harus dilengkungkan mengikuti lingkaran. Namun pada lingkaran dengan panjang jari-jari 1000 kilometer, tongkat akan terlihat berhimpit dengan lingkaran tanpa harus dilengkungkan tongkat. Seperti inilah perbedaan saf salat dalam Masjidil Haram yang harus dilengkungkan dan saf salat dalam masjid di Indonesia yang tidak harus dilengkungkan, karena jarak Indonesia dengan Ka'bah lebih 6000 kilometer. $^{26}$

Pergeseran lempengan bumi akibat tsunami dan gempa tektonik juga sering dijadikan kambing hitam dalam persoalan pergeseran arah kiblat masjid di Indonesia. Hasil penelitian menunjuki pergeseran arah kiblat akibat gempa tektonik hanya dalam sekala detik busur yang ditandai dengan berpidahnya data koordinat suatu lokasi. Pergeseran dalam skala detik tentunya tidak terpengaruh terhadap penetapan arah kiblat, karena pergeseran tidak lebih dari batas toleransi pelencengan arah kiblat untuk wilayah Indonesia yang bernilal sekitar 25 Menit busur. ${ }^{27}$ Untuk tsunami juga memiliki andil pergeseran arah kiblat yang relatif kecil akibat pergeseran lempengan bumi yang sedikit terangkat ke permukaan, hal ini dapat dijadikan contoh hasil penelitian di pulau Simeuleu-Aceh sebuah wilayah yang pernah dua kali dihantam tsunami besar yang mengakibatkan permukaan bumi terangkat 22 sentimeter yang mengakibatkan pergeseran arah kiblat sebesar 0,374 detik busur. ${ }^{28} \mathrm{Jadi}$ gempa bumi dan tsunami tidak berpengaruh terhadap posisi arah kiblat yang telah ditetapkan dan bisa disimpulkan bahwa bila masjid telah ditetapkan arah kiblat oleh ahli akan kekal arah kiblat tersebut sepanjang masa.

\section{Penutup}

Fatwa MPU Aceh Nomor 3 Tahun 2018 tentang penetapan arah kiblat merupakan ajaran fikih yang perlu ditaati dan dijadikan rujukan dalam persoalan arah kiblat di Aceh, di mana fatwa ini telah

\footnotetext{
26 Muh. Ma'rufin Sudibyo. 157-164.

27 Evi Dahliyatin Nuroini, "Pengaruh pergeseran lempeng bumi terhadap penentuan arah kiblat masjid-masjid di Kota Yogyakarta" (undergraduate, Universitas Islam Negeri Maulana Malik Ibrahim, 2010), http://etheses.uin-malang.ac.id/1899/.

28 Muh. Ma'rufin Sudibyo, Sang Nabi Pun Berputar, Arah kiblat dan tata cara pengukurannya. 153-156.
} 
terpenuhi unsur-unsur syarat ijtihad jama’i (ijtihad kolektif) dengan melibatkan ahli falak dalam perumusan fatwa. Dengan adanya sifat responsif, proaktif dan antisipatif, fatwa MPU Aceh Nomor 3 Tahun 2018 tentang penetapan arah kiblat mampu menyelesaikan masalah arah kiblat di Aceh, baik dalam ranah teknis, maupun pada ranah sosiologis. Di Indonesia, kehadiran fatwa MPU Aceh Nomor 3 Tahun 2018 tentang penetapan arah kiblat merupakan penyempurnaan terhadap fatwa MUI Nomor 3 dan Nomor 5 Tahun 2010 tentang arah kiblat yang dianggap fatwa prematur karena masih kurang dalam segi kolektif, proaktif dan antisipatif dalam persoalan arah kiblat.

Secara umum sifat fatwa MPU Aceh Nomor 3 Tahun 2018 tentang penetapan arah kiblat telah terpenuhi. Sifat responsif dalam mengeluarkan fatwa terlihat pada pertimbangan dikeluarkan fatwa yang tertulis dalam diktum a, b dan c, fatwa dikeluarkan sebagai respon terhadap situasi yang sedang terjadi dalam masyarakat akibat ada perbedaan pendapat dikalangan tokoh masyarakat tentang arah kiblat. Sifat proaktif dapat dilihat dari siap dan sigap dalam menyelesaikan masalah dengan melibatkan ahli falak dalam perumusan fatwa sebagai bentuk ijtihad kolektif dan mensosialisasikan kepada tokoh masyarakat setelah fatwa dikeluarkan. Sifat antisipatif dapat dilihat dari diktum fatwa yang mewajibkan setiap masjid yang akan dibangun untuk ditetapkan arah kiblat oleh ahli, hal ini agar tidak terulang masalah yang sama di masa yang akan datang dalam masyarakat tentang persoalan arah kiblat.

Fatwa MPU Aceh Nomor 3 tahun 2018 tentang penetapan arah kiblat sangat layak dan wajib dijadikan referensi dalam persoalan kiblat di Aceh, hal ini karena fatwa ini mampu menyelesaikan masalah dalam ranah tenknis dan sosiologis. Dengan diwajibkannya penetapan arah kiblat oleh ahli, menunjukkan bahwa secara teknis penetapan arah kiblat sudah tuntas dan tentu akan diakui hasilnya oleh ahli yang lain. Dengan melibatkan tokoh masyarakat dalam tim ahli penetapan arah kiblat dapat mempersatukan semua lapisan masyarakat dan akan menjadi referensi bagi masyarakat generasi selanjutnya dalam bentuk arsip berita acara penetapan arah kiblat yang dikeluarkan oleh Kementerian Agama RI Kabupaten atau Kota yang telah ditanda tangani oleh para tim ahli dan saksi. Mengabaikan fatwa ini berarti membiarkan permasalahan arah kiblat dalam masyarakat terus terpelihara yang sewaktu-waktu akan mengancam ukhuwah islamiah umat Islam.

\section{DAFTAR PUSTAKA}

Abdullah Ibrahim. Ilmu Falak: Antara Fiqih dan Astronomi. 1 ed. Yogyakarta: Fajar Pustaka Baru, 2017.

Ahmad Izuddin. Akurasi Metode-metode Penentuan Arah Kiblat. I. Jakarta: Kementerian Agama RI, 2012. Amir Syarifuddin. Ushul Fiqh. Pertama. Jakarta: Kencana, 2011.

Awaluddin, Moehammad, Bambang Darmo Yuwono, Hani'ah Hani'ah, dan Satrio Wicaksono. “Kajian Penentuan Arah Kiblat Secara Geodetis.” Teknik 37, no. 2 (31 Desember 2016): 84-87. https:// doi.org/10.14710/teknik.v37i2.12107.

Daud, Mohd Kalam, dan Muhammad Kamalussafir. “Akurasi Arah Kiblat Komplek Pemakaman Ditinjau Menurut Kaidah Trigonometri (Studi Kasus di Kecamatan Syiah Kuala Kota Banda Aceh)." Samarah: Jurnal Hukum Keluarga dan Hukum Islam 2, no. 2 (29 Mei 2019): 502-29. https:// doi.org/10.22373/sjhk.v2i2.4750.

Imam Khatib al-Syarboini. Mugni al-mukhtaj. 2 vol. Lebanon: Bairot, 2004.

Isa, Teungku Mustafa Muhammad. Fiqih Falakiyah. Yogyakarta: Deepublish, 2016. 
Ismail. "Standar Operasional Prosedur (SOP) Kalibrasi Arah Kiblat Masjid Di Era Digital." Al-Marshad: Jurnal Astronomi Islam Dan Ilmu-Ilmu Berkaitan 5, no. 1 (2 Juni 2019). https://doi.org/10.30596/ jam.v5i1.3126.

Jaelani, Achmad, Anisah Budiwati, Encep Abdul Rojak, Faqih Baidhawi, Mahya Laila, Hasna Tuddar Putri, Muhammad Manan Ma'nawi, Robi'atul Aslamiyah, Siti Muslifah, dan Siti Tatmainul Qulub. Hisab Rukyat Menghadap Kiblat (Fiqh, Aplikasi Praktis, Fatwa, dan Software). Pustaka Rizki Putra, 2012.

Kemenag RI. Ilmu Falak Praktik, 2013. http://simbi.kemenag.go.id/pustaka/images/ materibuku/ ilmu\%20falak\%20paraktik-2013.pdf.

Majelis Permusyawaratan Ulama. Fatwa MPU Aceh Nomor 3 Tahun 2018 Tentan Penetapan Arah Kiblat, Pub. L. No. 2018 (t.t.).

Majelis Ulama Indonesia. Fatwa MUI Nomor 3 Tahun 2010 Tentang Arah Kiblat (2010).

Muh. Ma'rufin Sudibyo. Sang Nabi Pun Berputar, Arah kiblat dan tata cara pengukurannya. Solo: Tinta Medina, 2011.

Nafi', Agus Yusrun. “Verifikasi Fatwa Mui Nomor 03 Tahun 2010 tentang Arah Kiblat.” Mahkamah: Jurnal Kajian Hukum Islam 9, no. 1 (26 Februari 2016). https://doi.org/10.24235/mahkamah. v9i1.289.

Nuroini, Evi Dahliyatin. "Pengaruh pergeseran lempeng bumi terhadap penentuan arah kiblat masjidmasjid di Kota Yogyakarta.” Undergraduate, Universitas Islam Negeri Maulana Malik Ibrahim, 2010. http://etheses.uin-malang.ac.id/1899/.

Rinto Anugraha. Mekanika Benda Langit. Yogyakarta: MIPA UGM, 2012.

Slamet Hambali. Ilmu Falak, Arah Kiblat Setiap Saat. Yogyakarta: Pustaka Ilmu, 2013.

Tanjung, Dhiauddin. "Urgensi Kalibrasi Arah Kiblat Dalam Penyempurnaan Ibadah Salat." Al-Manahij: Jurnal Kajian Hukum Islam 11, no. 1 (2017): 113-32. https://doi.org/10.24090/mnh.v11i1.1273. 